Allowance must be made, when the product is packed in a tin, for the penetration of heat to the deepest parts of the package; and the rate of penetration will vary considerably with the density of the contents, being much slower for meat than for a tin of fluid.

\section{Food PoIsoning}

A product canned by correct processes is one of the safest articles of diet it is possible to have, and many complaints made to manufacturers that their products have caused illness, have shown on investigation to have no justification. According to Prof. Tanner of Illinois (speaking at the Congress of Microbiology, 1936), in the past canners and distributors have tried to avoid publicity by settling their claims out of court. Medical practitioners are often un. familiar with the procedures necessary to establish definitely the causative factors in food poisoning. There is also much prejudice on the part of the public as well as ignorance of the great care generally taken in the manufacture of these products. It has been shown in Great Britain and the United States that by far the largest number of cases of food poisoning are caused by foods which have been prepared in the home or by products sold in a pre-cooked condition, but not sterilized.

\section{Tinplate Containers}

A difficulty, still not completely solved, is that of producing in commercial quantities the perfect tinplate for the construction of a can, or tin stopper for a glass jar. Then also, the machinery necessary in making the can may break the tin coating and expose the base metal, iron. The iron thus exposed may be attacked by the salt present in meat and vegetable products. An attempt has been made to produce a lacquer which when applied to the tinplate would prevent this action. Several difficulties have so far prevented the realization of this ideal.

\section{Preservation of Meat}

The preservation of meat by means of salts has long been practised, but only recently have its scientific principles been studied. The production of colour as well as preservation from putrefaction is brought about by the use of saltpetre. Bacterial action converts the nitrate of the saltpetre into nitrite, which combines with hæmoglobin, and when the meat is boiled the latter is converted into nitrohæmochromogen, which has the bright red colour characteristic of properly cured silverside. The micrococci responsible for this action can grow in media containing as much as 20 per cent of salt, in which concentrations the putrefactive bacteria cannot exist. Nor can their spores develop in media containing as much as 10 per cent of salt.

\section{Chocolate and Confectionery}

Changes in atmospheric temperature and humidity are liable to produce changes in chocolate and confectionery. The British Food Manufacturers' Research Association has given manufacturers a great deal of help in determining the conditions necessary for the production and storage of satisfactory chocolate. In the factory, it is generally possible to secure these conditions, but in retail premises it is not so easy. If the manufacturer were able to deliver his goods direct from his warehouse to the consumer, defective products would not be so commonly seen as they are at the present time.

\title{
Conduction of Electricity in Solids
}

\section{Conference at Bristol}

\begin{abstract}
A CONFERENCE on the "Conduction of Electricity in Solids" was held at Bristol on July 13-16 under the joint auspices of the Physical Society and the University of Bristol. The discussions were opened by R. W. Pohl, who gave an account of the fundamental work on electron conductivity and photochemical processes in alkali-halide crystals carried out in his laboratory at Göttingen. The paper was mainly concerned with the properties of crystals which have been coloured either by heating in alkali vapour or in other ways, introducing colour centres called ' $F$ 'centres'. A discussion followed on the exact nature of these $F$-centres, and, although there is as yet no certainty on this point, a hypothesis was proposed which seemed to have a good deal to recommend it, namely that an $F$-centre is an electron localized at a point in the lattice where a negative ion is missing.

Papers on phosphorescence in halide and sulphide crystals were given by R. Hilsch (Göttingen) and J. T. Randall (General Electrical Co., Ltd.) who discussed to what extent this phenomenon is related
\end{abstract}

to photoconductivity and to the transference of an electron to a large distance from the phosphorescent centre.

J. H. de Boer (Eindhoven) gave a paper by himself and E. J. W. Verwey on semi-conductors with partially filled $3 d$-bands. He pointed out that the electron theory of metals in its present form is not applicable to a substance such as nickel monoxide, in which a 'band' of electron states is incompletely filled, and therefore ought to behave like a metallic conductor, but which has in fact a resistance some $10^{9}$ times greater than a metal. Both he and $\mathrm{R}$. Peierls gave indications of the way in which the theory would have to be modified to include these substances.

Subsequent papers dealt with conduction in metals. G. Borelius gave an account of the work carried out at his Institute in Stockholm on the resistance of alloys, and especially of alloys in which the atoms can take up an ordered or disordered arrangement. His own pioneer work on the treatment of this prob. lem from the point of view of thermodynamics 
is described. W. L. Bragg gave a paper by himself, C. Sykes and A. J. Bradley on the work carried out at Manchester on the same problem.

C. H. Desch (National Physical Laboratory) gave a paper on age hardening alloys with special reference to their resistance. A. J. Bradley also mentioned his recent work on the crystal structure of the permanent magnets in the iron-nickel-aluminium alloy series, and in consequence of this a very definite model was proposed for the age hardening process, the atoms present in solid solution being supposed to collect together in groups still forming part of the erystal lattice of the original alloy. Such a process sets up intense strain, and hence hardens the alloy.

The final day was devoted to a discussion of the resistance of thin metallic films. After an initial paper by G. I. Finch (Imperial College of Science and Technology) on the structure of these films as revealed by electron diffraction, E. T. S. Appleyard gave a paper on work carried out in Bristol on their resistance, and A. Féry and M. J. Bernamont followed with papers on work done in Paris. A distinction was drawn between metals such as the alkalis which may form a fairly uniform layer over the surface upon which they are deposited, and metals such as mercury which apparently form islands. The mechanism by which the atoms can wander on a surface and form islands was discussed by J. E. Lennard-Jones. A point upon which no agreement was reached was the negative temperature coefficient of resistance of some films, and whether it is due to occluded gases.

Full reports of the principal papers given at this meeting, together with a summary of the discussions and the main conclusions reached, will be published in September in a special number of the Proceedings of the Physical Siociety.

\section{Beginnings of Western Science in Japan}

$\mathrm{A}^{\mathrm{T}}$ T the fellows' dinner held at University College, London, on April 30, Prof. Joji Sakurai, emeritus professor in the Imperial University of Tokyo, president of the Imperial Academy and of the National Research Council of Japan, replied to the toast of the new honorary fellow. In the course of his remarks, Prof. Sakurai said :

"If what I have been able to do in my work in Japan is at all creditable, the credit must be traced back to my education in England and, first and most of all, to the scientific training I received in University College during the five years extending from 1876 until 1881. Dr. Alex. W. Williamson, renowned throughout the whole world for his classical investigation on the formation of ethers and renowned also for his remarkably keen insight into the atomic constitution of matter, was then professor of chemistry, and it is needless for me to say how highly I value the scientific training I received from him. I was taught physics by Prof. Carey Foster and Dr. Oliver Lodge, and the knowledge of physics thus acquired was' a great help to me in following the remarkably rapid development of physical chemistry which was soon to come.

"It was, however, not the scientific training alone that $I$ received in England. The five years of my student life in England were in the latter half of Queen Victoria's reign, a period which is one of the most glorious in the whole history of England. It was a period in which some of the greatest and most illustrious of men and, also, of women were to be met with in almost every field of human activity. As statesmen and orators, Lord Beaconsfield and the grand old man-Mr. Gladstone-were shining like stars of first magnitude; Tennyson was being adored as poet laureate, Ruskin as a writer and critic and George Eliot as a feminine novelist of unusual talent ; Charles Darwin was enjoying to see his life-long labours bearing fruit, Herbert Spencer was laying a scientific foundation of sociology, whilst Henry Irving and Ellen Terry were, night after night, drawing crowds of enthusiastic audiences to the Lyceum.

"Having had the rare fortune of being in England at such a glorious time, I could not, and would not, confine myself to scientific studies alone, but wishing to look upon England with more widely opened eyes I studied something of English history, of English literature, of English art and, even, of English drama. At the same time, I had the great good fortune of making some very dear and life-long friends and, through them, of knowing something of English homes and of mixing more or less in English society, all of which combined in enabling me to get a fairly accurate idea of English culture, and it was this-the knowledge of English culture -which has proved to me to be of inestimable value throughout the whole of my later life. If, therefore, my work in Japan is worth mentioning, it is to be wholly attributed to the scientific and cultural training I was able to receive during the five years of my student life in England.

"I should like to make a short reference to an important fact in the recent history of Japan, concerning Anglo-Japanese cultural relations. A few years before the Restoration, that is about seventyfive years ago, a group of five young men from Choshu came over to London in one of the sailing vessels owned by Messrs. Jardine, Matheson \& Co. of Yokohama, whose correspondents in London were Messrs. Matheson \& Co. The object of these young men was to make a general study and observation of Western civilization and when, after a long voyage round the Cape of Good Hope, they arrived in London they were introduced to an elderly gentleman who took every care of them and helped them in every way in their study and observation. This elderly gentleman was no other than Dr. Williamson of University College under whom, as I said before, I was a student for five years. As to what made him particularly interested in these young men and in Japan I can say nothing, but I remember him. often telling me that Japan was England of the East, by which, as it appeared to me, he meant something more than mere geographical likeness of the two island empires.

"Returning to the five young men, two of them went back to Japan in the following year in consequence of important developments at home, and 